\title{
Description of three new species of Ceratocader (Hemiptera: Heteroptera: Tingidae) from Western Australia
}

\author{
Melinda L. Moir ${ }^{1}$ and Barbara Lis ${ }^{2}$ \\ ${ }^{1}$ ARC Centre for Excellence in Environmental Decisions, School of Botany, University of Melbourne, \\ Parkville, Melbourne, Victoria 3010, Australia. Email: mmoir@unimelb.edu.au \\ ${ }^{2}$ Department of Biosystematics, Opole University, Oleska 22, 45-052 Opole, Poland.
}

\begin{abstract}
This paper describes three new species of Ceratocader (Tingidae), almost doubling the number of known species. Ceratocader langlandsi sp. nov. is found in arid south Western Australia. In contrast, $C$. coatesi sp. nov. and $C$. bridgettae sp. nov. are found in the wetter tall forests of the far south-west of Western Australia. Notes on the genus, and its sister genus, Australocader, as well as a key to species of Ceratocader, are provided.
\end{abstract}

KEYWORDS: Cantacaderinae, coextinction, short-range endemic

\section{INTRODUCTION}

The endemic Australian lacebug genus Ceratocader Drake, 1950 (Hemiptera: Heteroptera: Tingidae) is currently represented by four described species. Ceratocader armatus (Hacker, 1928), the armed lacebug, is recorded from South Australia, and $C$. dentatus (Hacker, 1928), the dented lacebug, from northern Tasmania (Hacker 1928; Cassis and Gross 1995). Lis (2000) added a further two species: C. fulvus Lis, 2000 from the far south-west of Western Australia and C. monteithi Lis, 2000 (Monteith's lacebug) from central Queensland (Figure 1).

Western Australia is particularly rich in lacebug species of the family Tingidae, with a key to the genera present in the south-west provided by Moir and Guilbert (2012). Despite recent publications documenting new species (e.g. Cassis and Symonds 2008, 2011; Guilbert and Moir 2010; Moir 2009; Moir and Guilbert 2012) many species await description. Here, we describe three new species of Ceratocader from Western Australia: Ceratocader langlandsi sp. nov. from the arid southern region, plus $C$. coatesi sp. nov. and C. bridgettae sp. nov. from the far south-west of the State (Figure 1). In addition, a discussion on the genus and a key to species is provided.

\section{MATERIALS AND METHODS}

The specimens examined here were collected by beating, vacuum sampling or pitfall traps (see Langlands et al. 2006; Moir et al. 2005a; Orabi et al.
2010 for detailed descriptions of the methods and sites). Specimens are pinned and deposited in the Western Australian Museum, Perth (WAM), and the M.L. Moir personal collection, Perth (MLM).

Specimens were examined with an Olympus SZ51 stereo microscope, and all images were produced using a Leica MZ16 stereo microscope and the package Automontage Pro version 5.02(p) (Syncroscopy, Cambridge, U.K.). A map of species distribution was produced in ArcGIS Version 9.1 (Environmental Systems Research Inc.). Tingidae terminology follows Froeschner (1996) and Lis (2000), classification follows Guilbert (2012).

\section{SYSTEMATICS}

Family Tingidae Laporte, 1833

\section{Subfamily Cantacaderinae Stål, 1873}

Tribe Ceratocaderini Lis, 1999

Genus Ceratocader Drake, 1950

urn:Isid:zoobank.org:act:467D998F-7ECB-4BD7-8F832256582A46CB

Ceratocader Drake, 1950: 157.

\section{TYPE SPECIES}

Cantacader armatus Hacker, 1928 by original designation. 


\section{REMARKS}

Tingid taxonomy is based solely on the external morphology, often without any description of the genitalia, which are minimally diagnostic (Froeschner 1996; Lis 2000). Ceratocader was previously distinguished from other genera within the subfamily Cantacaderinae by the combination of the following characters: exposed scutellum, presence of 6-8 long spines on the lateral margins of the paranotum, and the anterior margin of the pronotum projecting a small to medium hood over the head (Froeschner 1996; Lis 2000). However, taking into account the features of the species described herein, we redefine the genus to include Cantacaderinae species with 3-8 spines on the lateral margins of the paranotum, and the pronotal hood present or absent (e.g. Figures 8-13).

\section{KEYTO SPECIES OF CERATOCADER (ADAPTED FROM LIS, 2000)}

1. Lateral spines on paranotum not longer than the diameter of the eyes (Figure 9) 2

At least one pair of lateral spines on paranotum longer than the diameter of the eyes (Figures 10-13)

2. Three well-defined lateral spines on paranotum (Figure 9) Ceratocader langlandsi

Lateral spines on paranotum very small, almost non-existent, but number more than three Ceratocader dentatus

3. Costal area recurved over onto itself (Figures 6,7) Ceratocader bridgettae

No part of costal area recurved over onto itself ....... 4

4. Base of posterior cephalic spines distinctly one eye length in front of eyes (Figure 13)

Ceratocader fulvus

Base of posterior cephalic spines almost touching eyes (Figure 12) 5

5. Hood projecting over head (Figure 11). Posterior part of paranotum expanded and forming lobe bearing $4-5$ rows of aerolae Ceratocader armatus

Hood not projecting over head (Figure 8). Posterior part of paranotum not expanded 6

6. Anterior paranotal spine not surpassing eyes in length (Figure 12) Ceratocader monteithi

Anterior paranotal spine surpassing eyes in length (Figure 8) Ceratocader coatesi

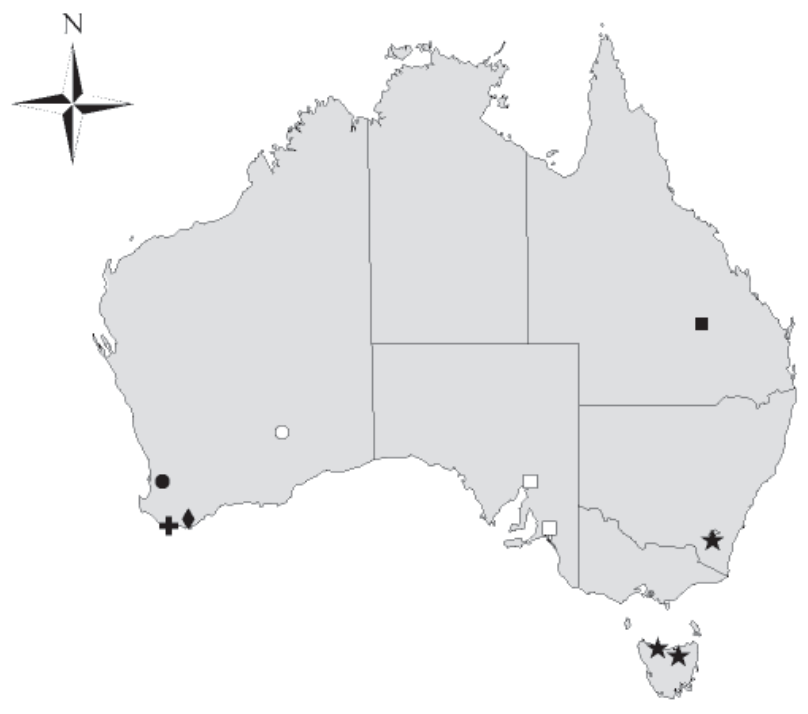

FIGURE 1 Map of Australia with collection localities of Australian Ceratocader species. Symbols represent the following: stars $-C$. dentatus; white squares $-C$. armatus; black square $-C$. monteithi; cross - C. fulvus; diamond - C. coatesi; white circle - C. langlandsi; and black circle - C. bridgettae.

\section{Ceratocader langlandsi sp. nov.}

urn:Isid:zoobank.org:act:5508DE89-0F8C-4E5DA126-42EF035B7F69

Figures 1-3, 9

\section{MATERIAL EXAMINED}

\section{Holotype}

Australia: Western Australia: $\widehat{\alpha}$, Queen Victoria Springs Nature Reserve, night beating, 30¹4'S, $123^{\circ} 41^{\prime} \mathrm{E}, 21$ March 2003, P.R. Langlands (WAM E82993).

\section{Paratype}

Australia: Western Australia: 1 ते, 1 \&, same as holotype (WAM E82994, WAM E82763).

\section{Other material examined}

Australia: Western Australia: 1 o same as holotype (MLM 205).

\section{DIAGNOSIS}

Ceratocader langlandsi is most similar to C. fulvus, but the two differ in the length and number of lateral spines on the paranotum; $C$. langlandsi has three medium spines per lateral margin which are all shorter than the diameter of the eye, whereas C. fulvus has approximately seven spines of varying lengths, but at least one spine of equal length to the diameter of the eye (see Figures 3, 9). Also, C. fulvus has a prominent hood, whereas $C$. langlandsi has not. 


\section{DESCRIPTION}

Body measurements. ô $5.96 \pm 0.24 \mathrm{~mm}(\mathrm{n}=3)$, q 5.80 $\mathrm{mm}(\mathrm{n}=1)$.

Colour. Eyes dark red. Body, genital capsule, 4th antennal segment, femur, distal half of tibia and markings on hemelytra (particularly band across costal region, almost midway down hemelytra) dark brown. Head, hemelytra, and pronotum golden brown. Pronotum and hemelytra (particularly main veins) infused with orange (Figure 2). Remaining antennal segments and legs brown.

Head and antennae. Head with 4 long, cephalic spines, surpassing 2nd antennal segment (Figures 2, 3). Antenniferous process slender and pointed, not surpassing 1st antennal segment. Antennae slender, antennal segments measurements: I, $0.12 \mathrm{~mm}$; II, $0.10 \mathrm{~mm}$; III, $1.90 \mathrm{~mm}$; IV, $0.30 \mathrm{~mm}$. Fourth antennal segment pilose. Rostrum long, extending to 4 th visible abdominal segment.

Body. Coleopterous. Pronotum large, posterior margin bisinuate; anterior margin raised slightly over head but lacking obvious hood; three carina, each uniseriate. Lateral carina broken at one-fifth length from anterior margin of pronotum, with large gap and small spine projecting upward from anterior edge of break. Paranota large, widest at midlength, triseriate (Figure 2). Pronotum with 3 short (less than the diameter of an eye) lateral spines per side (Figures 2, 9). Forewings (or hemelytra) much wider than pronotum, extending out approximately half the width of the pronotum. Lateral margins of forewings raised and slightly recurved (Figure 2). Posterior margin rounded. Scutellum exposed, represented as a relatively large, round knoblike process, elevated above hemelytra. Stenocostal region present with one row of small round areolae, costal region with on average eight small round areolae and subcostal with six to eight rows of areolae. Hind wings absent.

Nymphs. unknown

\section{ETYMOLOGY}

This species is named in honour of the collector, Dr Peter Langlands, for his continued enthusiasm in collecting new and interesting species of Hemiptera, often from relatively inaccessible regions of Western Australia.

\section{COMMON NAME}

Langlands' lacebug.

\section{Ceratocader coatesi sp. nov.}

urn:Isid:zoobank.org:pub:14E1F58D-47BE-4839-85EC8CEEF76FBAC8

Figures 1, 4, 5, 8

\section{MATERIAL EXAMINED}

\section{Holotype}

Australia: Western Australia: $\hat{\partial}$, Porongurups National Park, Devils Slide, site 6, 3440'31"S, $117^{\circ} 51^{\prime} 05^{\prime \prime E}$, ex Gastrolobium crenulatum [Note: plant species misidentified $=G$. subcordatum], beat, 15 October 2006, M.L. Moir and J.M. Waldock (WAM E82995).

\section{DIAGNOSIS}

Ceratocader coatesi resembles both C. monteithi and C. armatus, but differs from both species by fewer (c. 5) spines per lateral margin of the paranotum, with the anterior spine long, extending forward and surpassing the eyes (see Figures 4, 8).

\section{DESCRIPTION}

Body measurements. $\widehat{\jmath} 3.80 \mathrm{~mm}(\mathrm{n}=1)$.

Colour. Eyes red. Collar region, 4th antennal segment and markings on hemelytra (particularly band across costal region near middle of hemelytra) dark brown. Head, body, hemelytra, genital capsule, pronotum, remaining antennal segments and legs golden brown. Cephalic spines, pronotum, hemelytra and body infused with orange (Figure 4).

Head and antennae. Head with four long, cephalic spines, surpassing 2nd antennal segment (Figures 4, 8). Antenniferous process slender and pointed, not surpassing 1st antennal segment. Antennae slender, antennal segments measurements: I, $0.10 \mathrm{~mm}$; II, $0.07 \mathrm{~mm}$; III, $1.20 \mathrm{~mm}$; IV, $0.20 \mathrm{~mm}$. Fourth antennal segment pilose. Rostrum extending to 1 st visible abdominal segment.

Body. Coleopterous. Pronotum large, posterior margin bisinuate; anterior margin raised slightly over head but lacking obvious hood; 3 carina consisting of one row of areolae. Lateral carina discretely broken (without gap) at one-fifth length from anterior margin of pronotum. Paranota large, widest in anterior half, consisting of 3 rows of round areolae (Figure 4). Pronotum with 6-7 lateral spines per side of varying lengths; anterior spine the longest, surpassing eyes (Figures 4,8 ). Forewings (or hemelytra) wider than pronotum, extending out approximately a quarter the width of the pronotum. Lateral margins of forewings raised (Figure 4). Scutellum exposed, represented as a small rounded rectangular process, elevated slightly above hemelytra. Stenocostal region present with 1 row of small round areolae, costal region with 4 to 5 rows of small round areolae and subcostal with 6 rows of areolae. Hind wings present.

\section{Nymphs. Nymphs unknown.}

\section{ETYMOLOGY}

This species is named in honor of Dr David Coates, for his contribution towards the conservation of many threatened Western Australian plant species, and his support of the first author's work highlighting the potential coextinction of insects on these plants. 

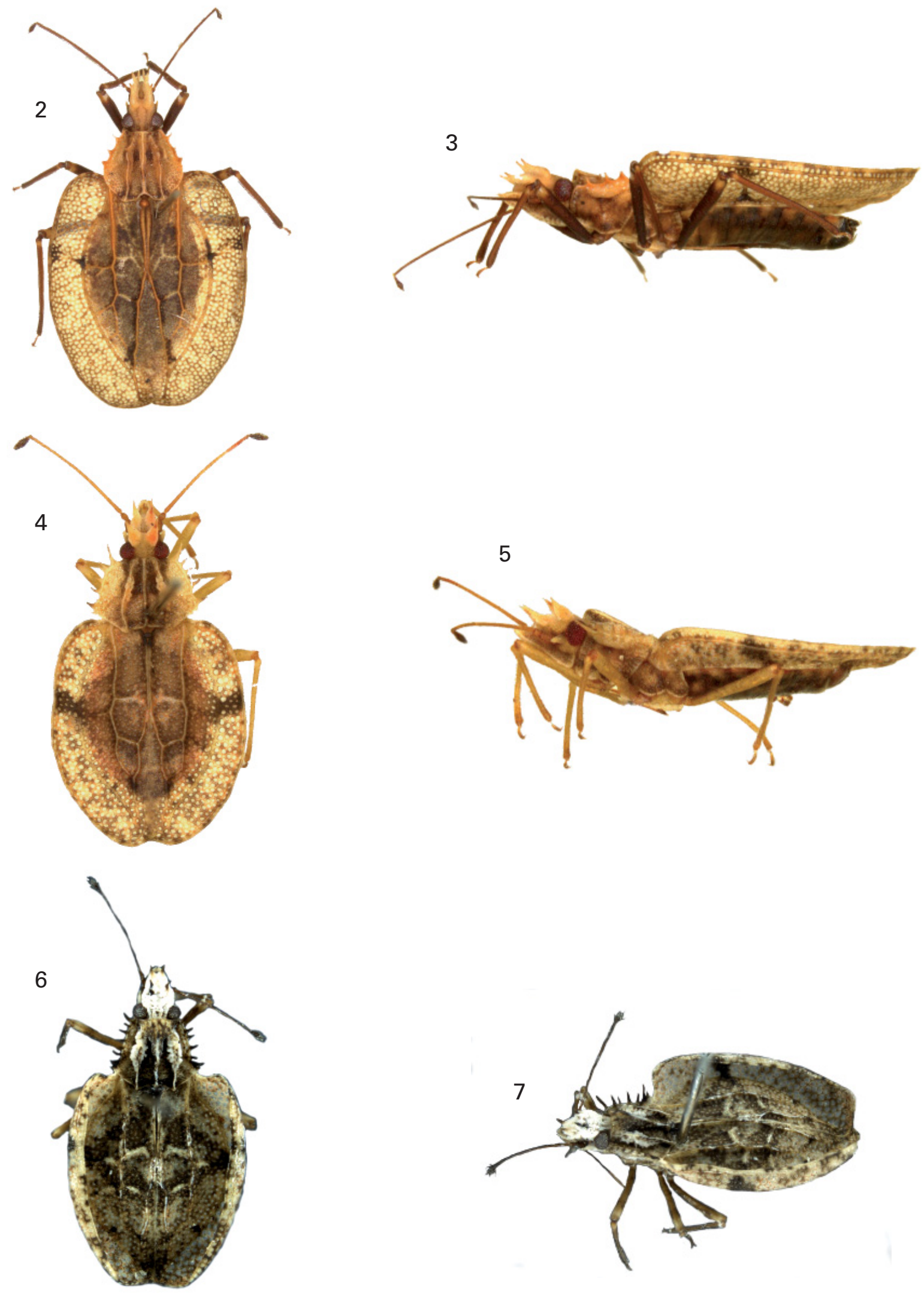

FIGURES 2-7 Dorsal and lateral views of the three new species of Ceratocader. 2, 3, C. langlandsi sp. nov. (MLM 205); 4, 5, C. coatesi sp. nov. holotype (WAM 82995); 6, 7, C. bridgettae sp. nov. paratype (WAM 82997). 

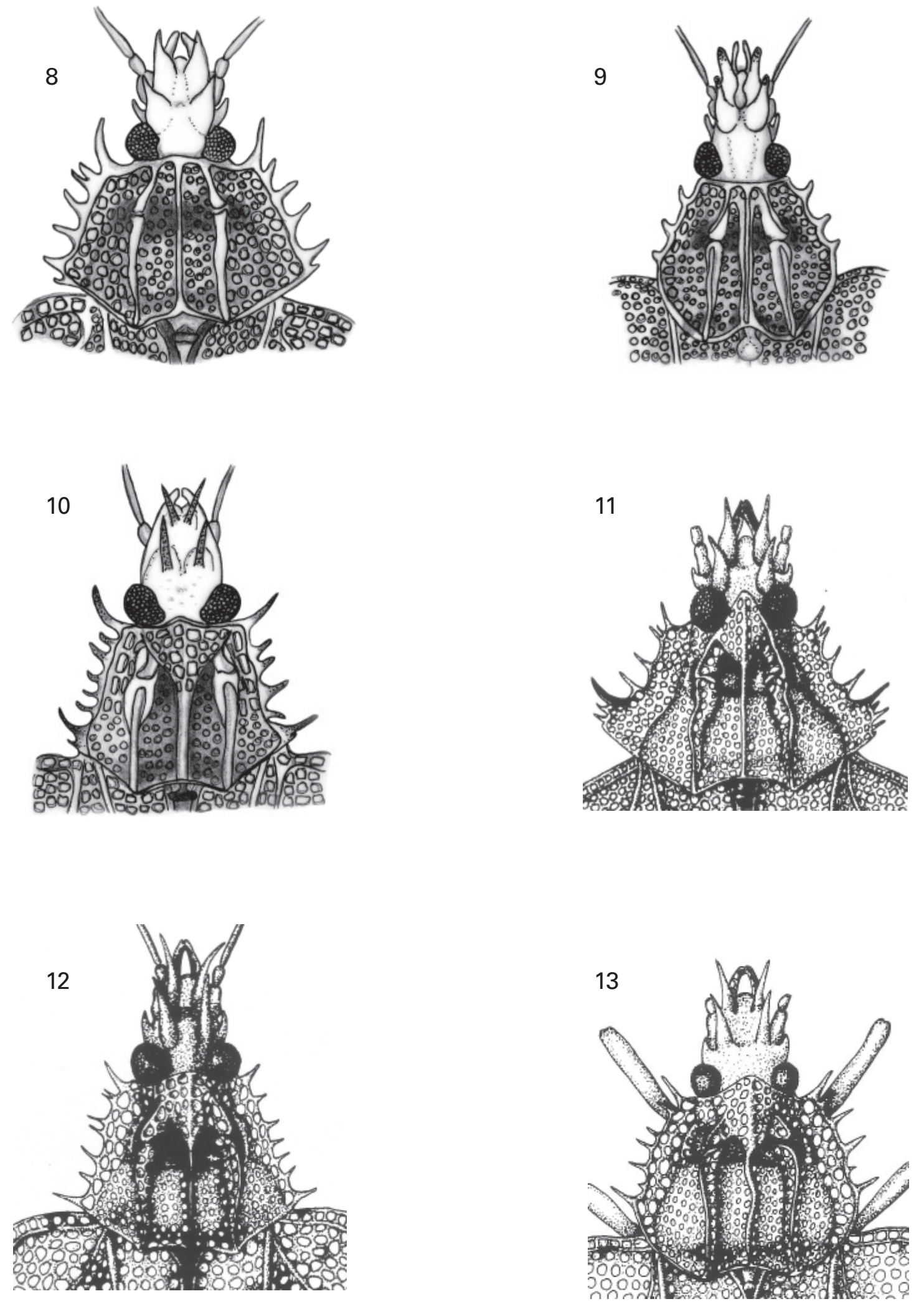

FIGURES 8-13 Head and pronotum of Ceratocader spp.: 8, C. coatesi sp. nov.; 9, C. langlandsi sp. nov.; 10, C. bridgettae sp. nov.; 11, C. armatus; 12, C. monteithi; 13, C. fulvus. Figures 11, 12 and 13 adapted from Lis (2000), copyright Wiley-VCH Verlag GmbH \& Co. KGaA; reproduced with permission. 


\section{COMMON NAME}

Coates' lacebug.

\section{Ceratocader bridgettae sp. nov.}

urn:Isid:zoobank.org:pub:14E1F58D-47BE-4839-85EC8CEEF76FBAC8

Figures 1, 6, 7, 10

\section{MATERIAL EXAMINED}

\section{Holotype}

Australia: Western Australia: $\hat{\sigma}$, Boddington, site NP96 (mine), pitfall trap, April 2003, G. Orabi (WAM E82996).

\section{Paratype}

Australia: Western Australia: 19 , Boddington, site MO4J (Jarrah forest), litter sample, April 2004, G. Orabi (WAM E82997).

\section{DIAGNOSIS}

Ceratocader bridgettae could be confused with $C$. dentatus, but differs from the latter by having the costal region of the hemelytra curved up and back upon itself (also termed 'recurved') for almost the entire length, whereas the costal region of $C$. dentatus is only recurved in anterior half (Hacker, 1928). In addition, $C$. dentatus has only six short pronotal spines, shorter than the diameter of the eye (Froeschner, 1996), whereas $C$. bridgettae has 6-8 spines with at least one spine longer than the diameter of the eye.

\section{DESCRIPTION}

Body measurements. ô $3.83 \mathrm{~mm}(\mathrm{n}=1)$, $3.94 \mathrm{~mm}$ $(\mathrm{n}=1)$.

Colour. Eyes red. Body, genital capsule, 4th antennal segment, majority of lateral paranotum spines and markings on hemelytra (particularly band across costal region almost midway down hemelytra) dark brown. Cephalic spines and lateral carina on pronotum surrounded by white 'foam-like' substance (Figures 6,7). Head, body, hemelytra, pronotum, legs and remaining antennal segments yellow-brown.

Head and antennae. Head with four long, cephalic spines, surpassing 2nd antennal segment (Figure 6). Antenniferous process slender and pointed, not surpassing 1st antennal segment. Antennae slender, antennal segments measurements: I, $0.10 \mathrm{~mm}$; II, $0.08 \mathrm{~mm}$; III, $1.35 \mathrm{~mm}$; IV, $0.20 \mathrm{~mm}$. Fourth antennal segment pilose. Rostrum extending to 1 st visible abdominal segment.

Body. Coleopterous. Pronotum large, posterior margin bisinuate; 3 carina uniseriate for most of length. Lateral carina broken at one-fifth length from anterior margin of pronotum. Hood present, inflating approximately half of central pronotal carinae, projecting slightly over head. Paranota consisting of 2 rows of square areolae for almost entire length (Figure 6). Pronotum with 6-8 lateral spines per side of varying lengths; anterior spine the longest, almost surpassing eyes (Figures 6,10 ). Forewings (or hemelytra) wider than pronotum, extending out approximately a quarter the width of the pronotum. Lateral margins of forewings raised and recurved to such an extent that underside is visible when viewed dorsally (Figures 6,7). Scutellum exposed, represented as a small rectangular process, elevated above hemelytra. Stenocostal region present with 1 row of small round areolae, costal region with on average 6 rows of small round areolae and subcostal with 7 rows of areolae. Hind wings present.

Nymphs. Nymphs unknown.

\section{ETYMOLOGY}

This species is named in honor of Bridgette Brennan, the first author's eldest daughter.

\section{COMMON NAME}

Bridgette's lacebug.

\section{DISCUSSION}

Ceratocader is closely related to other Gondwanan Cantacaderini genera, in particular the Australian Australocader Lis, 1997, and more distantly, the Australian Allocader Drake, 1950, Brazilian Nectocader Drake, 1928 and New Caledonian Caledoderus Guilbert, 2012 (Lis 1999; Schuh et al. 2006; Guilbert 2012). Ceratocader has been considered a primitive group of Cantacaderinae by Zhang et al. (2005), because species supposedly retain the basal cell of the hemelytron. These authors, however, only examined the illustration of C. armatus in Froeschner (1996, figure 7 ), the venation of which differs considerably from that given by Lis (2000, figure 3 ). The latter does not show a well defined, separate basal cell.

Both Ceratocader and the closely related Australocader have not been discovered outside Australia to date. The two genera differ in their distribution within Australia, with Australocader restricted to the east coast of the mainland. In contrast, Ceratocader has dispersed across Australia, including Tasmania, and has a hotspot of endemism in the Western Australian South-West (four of seven species found here: Figure 1). The distribution of the genus across Australia indicates that species may not be dispersal inhibited, and this is further supported by the collection of $C$. bridgettae in a relatively recently restored mine pit (9 year-old) (Orabi et al. 2010). In addition, the capture of $C$. monteithi in intercept traps (Lis 2000) suggests good powers of dispersal via flight. Paradoxically, however, a number of species $(C$. langlandsi, C. dentatus, C. fulvus, C. monteithi) lack hind wings and cannot fly. Presumably all of these species would not be able to disperse far by walking, and there is evidence that Ceratocader may represent short-range endemic species restricted to specific 
refugial sites (see below). But there are two perplexing contradictions to the suggestion that Ceratocader species without hind wings are dispersal inhibited: 1 . how were two specimens of $C$. monteithi captured by intercept traps?; and 2. the new locality record that we present here of $C$. dentatus on mainland Australia, in highlands in the Australian Capital Territory, results in a very wide distribution for a species lacking hind wings (Figure 1).

Ceratocader species are found in a variety of habitat types and rainfall climes (e.g. arid, C. langlandsi; cool and wet temperate, $C$. dentatus; temperate, C. bridgettae and $C$. armatus). Despite this, and their occurrence across most states of Australia, few specimens of the genus have been collected. Most species are known only from a single locality (Figure 1). As such, it is highly likely that Ceratocader are restricted to specific habitat types represented at these localities. For example, C. monteithi has been identified as a possible shortrange relictual species endemic to Carnarvon National Park in Queensland (Grant 2005). A restricted range also appears to apply to all new species described here. Ceratocader coatesi is found in the most northeastern disjunct population of wet Karri (Eucalyptus diversicolor F. Muell.) forest of the Porongurups National Park (for a discussion of the biotic and abiotic features of the National Park see Wills and Abbott, 2003). This area not only features a distinct genetic population of Karri (Coates and Sokolowski, 1989), but is a recognised hotspot of endemism for other invertebrates due to its high rainfall and mountainous terrain (e.g. Moir et al. 2009), and as a historical refugium for invertebrates from past sea level changes and aridity (Main 1999). Ceratocader langlandsi is found at Queen Victoria Springs Nature Reserve, which is recognised as a unique area where several habitat types overlap and result in high plant diversity (Langlands et al. 2006). Ceratocader bridgettae is found in the northern Jarrah (Eucalyptus marginata Sm.) forest, which has a relatively high rainfall when compared to surrounding northern, eastern and western areas (Orabi et al. 2010).

It is possible that the perceived rarity of Ceratocader is a result of collectors' under-sampling the preferred host plant species, and thus individuals have been collected as tourists on other plants, or opportunistically via pitfall traps, litter samples and intercept traps. However, in several localities in south-west Australia (e.g. Jarrahdale, Boddington, Stirling Range National Park, Ravensthorpe, south coastal region) many plants have been sampled intensively as part of other surveys without a single occurrence of a Ceratocader individual (Moir et al. 2005a, 2005b, 2010; Framenau et al. 2008; Moir et al. unpublished data). Thus, the reasons behind the rarity of Ceratocader remain a mystery. Interestingly, four specimens of C. langlandsi were caught by beating an unknown plant at night (P.R. Langlands, personal communication 2012). For this species at least, this could suggest that individuals feed on host plants at night and potentially shelter elsewhere during the day (perhaps in leaf litter, as the area where $C$. langlandsi was collected was long unburnt: P.R. Langlands, personal communication 2012). Furthermore, C. coatesi was captured on Gastrolobium subcordatum (Benth.) G. Chandler and Crisp, a plant which is considered rare (see http://florabase.dec.wa.gov. au/browse/profile/20507 and Chandler et al. 2002). Therefore, $C$. coatesi may be restricted in range due to the small range of the host plant and could require conservation itself (co-threatened: Moir et al. 2011). However, no conclusion is possible as yet because only one specimen has been found. Further study and collecting of these elusive lacebugs is ultimately required to answer questions concerning habitat requirements, dispersal potential, host plant preferences and their possible requirement for conservation.

\section{ACKNOWLEDGEMENTS}

We thank Mark Harvey and Volker Framenau (WAM) for assistance with the auto-montage package, and Murray Fletcher for providing comments on an earlier draft. We are grateful to the respective collectors of the Ceratocader specimens for allowing us access to study them. A grant from the National Climate Change Adaptation Research Facility (NCCARF) supported this work. Finally, we greatly appreciate the efforts to improve earlier versions of this paper by Mark Harvey and Eric Guilbert.

\section{REFERENCES}

Cassis, G. and Gross, G.F. (1995). Hemiptera: Heteroptera (Coleorrhyncha to Cimicomorpha). CSIRO Australia, Melbourne.

Cassis, G. and Symonds, C. (2008). Systematics, biogeography and host associations of the lace bug genus Inoma (Hemiptera: Heteroptera: Tingidae). Acta Entomologica Musei Nationalis Pragae 48: 433-484.

Cassis, G. and Symonds, C. (2011). Systematics, biogeography and host plant associations of the lace bug genus Lasiacantha Stål in Australia (Insecta: Hemiptera: Heteroptera: Tingidae) Zootaxa 2818: 1-63.

Chandler, G.T., Crisp, M.D., Cayzer, L.W. and Bayer, R.J. (2002). Monograph of Gastrolobium (Fabaceae: Mirbelieae). Australian Systematic Botany 15: 619-739.

Coates, D. and Sokolowski, R. (1989). Geographic patterns of genetic diversity in Karri (Eucalyptus diversicolor F. Muell.). Australian Journal of Botany 37: 145-156.

Drake, C.J. (1950). Concerning the Cantacaderinae of the world (Hemiptera: Tingidae). Arthropoda 1:153-166.

Drake, C.J. and Ruhoff, F.A. (1965). Lacebugs of the world: A catalogue (Hemiptera: Tingidae). U.S. National Museum Bulletin 243: 1-634.

Framenau, V.W., Moir, M.L. and Harvey, M.S. (2008). Terrestrial invertebrates of the south coast region of Western Australia: short-range endemics in Gondwanan relictual habitats. Unpublished Report. Western Australian Museum, Perth.

Froeschner, R.C. (1996). Lace bug genera of the world I: 
Introduction, subfamily Cantacaderinae (Heteroptera: Tingidae). Smithsonian Contributions to Zoology 57: 1-43.

Grant, C. (2005). Carnarvon National Park Management Plan. Queensland Parks and Wildlife Service, Environmental Protection Agency, Queensland, Brisbane. Pp. 55.

Guilbert, E. (2012). Phylogeny of Cantacaderinae Stål (Insecta: Heteroptera: Tingidae) revisited after the description of a new genus and new species from New Caledonia. European Journal of Entomology 109: 111-116.

Guilbert, E. and Moir, M.L. (2010). A new species of Carldrakeana (Insecta: Heteroptera: Tingidae) from Western Australia Records of the Western Australian Museum 25: 382-386.

Hacker, H. (1928). Species and records of Australian Tingitoidea (Hemiptera). Memoirs of the Queensland Museum 9: 174-188.

Langlands, P.R., Brennan, K.E.C. and Pearson, D.J. (2006). Spiders, spinifex, rainfall and fire: Long-term changes in an arid spider assemblage. Journal of Arid Environments 67: $36-59$.

Laporte, F. (1833). Essai d'une classification systématique de l'ordre des Hémiptères (Hémiptères Hétéroptères, Latr.). Magasin de Zoologie 2: 1-88.

Lis, B. (1999). Phylogeny and classification of Cantacaderini (=Cantacaderidae stat. nov.) (Hemiptera: Tingoidea). Annales Zoologici 49: 157-196.

Lis, B. (2000). A review of the genus Ceratocader Drake, with description of two new species (Heteroptera, Cantacaderidae). Mitteilungen aus dem Museum fur Naturkunde in Berlin - Deutsche Entomologische Zeitschrift. 2: 131-135.

Main, B.Y. (1999). Biological anachronisms among trapdoor spiders reflect Australia's environmental changes since the Mesozoic. In: Ponder, W., Lunney, D. (Eds.), The other 99\%: The conservation and biodiversity of invertebrates. The Royal Zoological Society of New South Wales, Sydney, pp. 236-245.

Moir, M.L. (2009). Two new species of the lacebug genus Radinacantha (Hemiptera: Heteroptera: Tingidae) from Australia. Records of the Western Australian Museum 25: 382-386.

Moir, M.L., Brennan, K.E.C., Majer, J.D., Koch, J.M. and Fletcher, M.J. (2005a). Toward an optimal sampling protocol for Hemiptera on understorey plants. Journal of Insect Conservation 9: 3-20.
Moir, M.L., Brennan, K.E.C., Koch, J.M., Majer, J.D. and Fletcher, M.J. (2005b). Restoration of a forest ecosystem: the effects of vegetation and dispersal capabilities on the reassembly of plant-dwelling arthropods. Forest Ecology and Management 217: 294-306.

Moir, M.L., Brennan, K.E.C. and Harvey, M. S. (2009). Diversity, endemism and species turnover of millipedes within the southwest Australia global biodiversity hotspot. Journal of Biogeography 36: 1958-1971.

Moir, M.L., Brennan, K.E.C., Majer, J.D., Koch, J.M. and Fletcher, M.J. (2010). Plant species redundancy and the restoration of fauna habitat: Lessons from plant-dwelling bugs. Restoration Ecology 18: 136-147.

Moir, M.L., Vesk, P.A., Brennan, K.E.C., Keith, D.A., McCarthy, M.A. and Hughes, L. (2011). Identifying and managing cothreatened invertebrates through assessment of coextinction risk. Conservation Biology 25: 787-796.

Moir, M.L. and Guilbert, E. (2012). Swaustraltingis isobellae, a new genus and new species of Australian lacebug (Insecta: Heteroptera: Tingidae), with a redescription of Cysteochila cracentis Drake, 1954 and notes on the lacebug fauna of south-west Australia. Australian Journal of Entomology 51: 258-265.

Orabi, G., Moir, M.L. and Majer, J.D. (2010). Assessing the success of mine restoration using Hemiptera as indicators. Australian Journal of Zoology 58: 243-249.

Schuh, R.T., Cassis, G. and Guilbert, E. (2006). Description of the first recent macropterous species of Vianaidinae (Heteroptera: Tingidae) with comments on the phylogenetic relationships of the family within the Cimicomorpha. Journal of the New York Entomological Society 114: 38-53.

Stål, C. (1873). Enumeratio Hemipterorum. 3. Kungliga Svenska Vetenskapsakademiens Handlingar (N.F.) 11: 1-163.

Wills, A. and Abbott, I. (2003). Landscape-scale species richness of earthworms in the Porongurup Range, Western Australia: influence of aspect, soil fertility, and vegetation type. Biology and Fertility of Soils. Springer, Berlin / Heidelberg, pp. 94-102.

Zhang, J., Golub, V. B., Popov, Y. A. and Shcherbakov, D. E. (2005). Ignotingidae fam. nov. (Insecta: Heteroptera: Tingoidea), the earliest lace bugs from the upper Mesozoic of eastern China. Cretaceous Research 26: 783-792.

MANUSCRIPT RECEIVED 7 MARCH 2012; ACCEPTED 3 SEPTEMBER 2012. 